\title{
Social Media Use and its Association with Sexual Practices among Undergraduate students in a Private Medical University at Solan, Himachal Pradesh
}

\section{Arjit Kumar $^{1}$}

${ }^{1}$ Associate Professor, Department of Community Medicine, Veer Chandra Singh Garhwali Government Institute of Medical Sciences and Research, Srinagar, Pauri Garhwal, Uttarakhad, India.

Correspondence : Dr Arjit Kumar, Email: drarjitkumar@gmail.com

\begin{abstract}
:
Introduction: Social networking has become integral to the intellectual and social lives of the young populace. Their often unrestricted access to sexually explicit content and associated adverse sexual health constitute key outcomes in public health research. Objectives: To determine the association between social media use and various sexual practices among undergraduate students in a private medical university at Solan, Himachal Pradesh. Method: We enrolled 300 undergraduates, using random sampling technique in the present cross sectional study. Data were collected using semi-structured questionnaire and data analysis employed statistical package for social sciences version 22.0. Chi-square test was used to determine association between variables and $p$ value $\leq 0.05$ was considered as statistically significant. Results: The mean age of respondents was $21.85 \pm 2.63$ years. Majority of the respondents have heard about social media $(\mathrm{n}=299,99.7 \%$ ) and majority have received information from friends/peers (79\%). The commonest reason for non-use of social media for sexually explicit content was lack of interest (54.3\%). The mean age at sexual debut was $17.44 \pm 2.63$ years. There was statistically significant association between use of social media for sexually explicit content and being sexually active $(\mathrm{p}=0.000)$, type of sexual acts practiced $(\mathrm{p}=0.003)$ and number of sexual partners $(\mathrm{p}=0.000)$. Conclusion: There is need for improved multi- sectoral measures (formal comprehensive sex education, peer education programs, school mini-media clubs and targeted behavior change intervention), Media and internet literacy education to control viewing of social media for sexually explicit content, while ensuring that young people's access to sexual health educational content is not compromised.
\end{abstract}

Key words: Sexual Practices, Social Media, Undergraduate

\section{Introduction:}

Several theories of media effects have documented the central place of content on influence of the media. One key source of risks from the manner in which humans experience and express their sexuality, is exposure to social media with sexually explicit content. ${ }^{[1]}$ Emerging evidence also suggests that social media affects sexual practices amongyoung people..$^{[2-5]}$

"Social media (or social networking) are interactive computer-mediated technologies that facilitate the creation and sharing of information,

\begin{tabular}{|c|l|l|}
\hline Quick Response Code & Access this article online & How to cite this article: \\
\hline Kumar A. Social media use and its association with \\
sexual practices among undergraduate students in a \\
private medical university at Solan, Himachal Pradesh. \\
Healthline.2021;12(1):37-45.
\end{tabular}


ideas, careers, interest and other forms of expression via virtual communities and networks. ${ }^{\text {"[] }}$ Since the advent of social networking sites, classmate.com, in 1995 and six degrees; in 1997, a plethora of social interaction outlets has flooded the internet space. ${ }^{[6-8]}$ These include: Facebook, WhatsApp, Twitter, etc. ${ }^{[9]}$

A paradigm shift in the delivery of digital interventions was the launch of internet access via smartphones and the development of apps for these phones. ${ }^{[10]}$ Researchers have reported increasingly easy access to sexually explicit content on the social media, coupled with dwindling sexuality education at homes or schools. ${ }^{[11]}$ They noted that social media can serve as useful tool in behaviour-change initiative received by digital routes. ${ }^{[10]}$ For instance, digital media interventions which are interactive and tailored (meaning that users receive tailored feedback in response to the input of person- specific relevant data), as active engagement with intervention and receipt of information that is of user-specific relevance is more likely to enhance consolidation of learning and behaviour change ${ }^{[10,12]}$

In this era of social media, commonly referred to as web $2.0,{ }^{[13]}$ acts such as meeting partners online, pornography online sexting (the sending of sexually explicit materials) are unlikely to convey positive sexual health messages. ${ }^{[10]}$

It is not unusual for social media users to be exposed to the risks, excessive masturbation, unprotected sexual act and multiple sexual partnerships at an early age. ${ }^{[11,14]}$ This trend had brought concerns among school authorities, parents, communication experts and other relevant stakeholders on the benefits and potential risks facing undergraduates, as they engaged in online social networking to meet their social and educational needs. ${ }^{[15,16]}$

Not much is known of the relationship between the social media use and sexual practices among undergraduates in Solan, Himachal Pradesh. ${ }^{[2,11]}$ Information about sexual practices is essential to the design and assessment of digital interventions to improve sexual health. ${ }^{[17,18]}$ The findings of this study will help educate the populace on healthful use of social media and as such bridge the knowledge gap on the associations between social media use and risky sexual practices. It will provide information for policy makers, government and non-government organizations working on young undergraduates sexuality issues. It is against this backdrop that the researchers designed this study to determine the use of social media and its association with risky sexual practices among undergraduate students in a private faith-based tertiary medical educational institution.

\section{Method:}

The present cross sectional descriptive study was done at MM Medical College \& Hospital which was established in 2013 as a constituent Institute of Maharishi Markandeshwar University, Solan. The study population comprised of all the medical students who were undertaking an undergraduate regular program at MMMC\&H for at least one year.

The sample size was determined using the formula $\mathrm{n}=\mathrm{Z}^{2} \mathrm{pq} / \mathrm{d}^{2{ }^{219]}}$ where $\mathrm{n}=$ minimum sample size; $\mathrm{Z}=$ standard normal deviate at $95 \%$ confidence interval set at 1.96; $\mathrm{p}=$ prevalence in a previous study; $q=1-p$; d=degree of precision (0.05); Thus using a prevalence from previous study done at Osogbo metropolis, Nigeria, which showed $73.5 \%$ as the prevalence rate, ${ }^{[2]}$ the sample size was estimated as 269.0. Assuming 10\% non response rate, the final sample size was approximately 300students.Simple random sampling technique using a table of random numbers, was applied to select 300 participants from 3000 medical under-graduates.

Data were collected using pre-tested, semistructured questionnaires developed from review of relevant literatures. All questions were written in English language and pre-tested at a site different from the study site. Thereafter the instruments were reviewed and necessary corrections were made.

Variables comprised of socio-demographic variables such as respondent's age, gender, religion, 
tribe, etc., awareness, reason for social media use and various sexual practices. The data were edited and entered into the computer. Data cleaning was done by carrying out range and consistency checks. Descriptive and analytical statistics of the data were carried out using International Business Machine/statistical package for social sciences (IBM/ SPSS) Windows version 22.0 (22). Descriptive data were presented as simple frequencies and percentages. Tests of statistical significance were carried out using Chi square tests; $p$ value of $\leq 0.05$ was considered statistically significant.

\section{Results:}

Three hundred medical under-graduates were approached and questionnaires were distributed. The response rate was thus analyzed to be $100 \%$. The mean age of respondents was $21.85 \pm 2.63$ years. The modal age group was 21-26 years (40.7\%), majority $(64.7 \%)$ were females, were never married (93.7\%) and were Christians (97.3\%). (Table-1)

Table 1: Distribution of the respondents by socio-demographic characteristics

\begin{tabular}{|c|c|c|}
\hline Characteristics & Frequency $(\mathrm{N}=300)$ & Percentage (\%) \\
\hline \multicolumn{3}{|c|}{ Age (in years) } \\
\hline $16-20$ & 110 & 36.7 \\
\hline $21-25$ & 149 & 49.7 \\
\hline $26-30$ & 41 & 13.6 \\
\hline No & 139 & 66.19 \\
\hline \multicolumn{3}{|c|}{ Gender } \\
\hline Male & 106 & 35.3 \\
\hline Female & 194 & 64.7 \\
\hline \multicolumn{3}{|c|}{ Marital status } \\
\hline Never married & 281 & 93.7 \\
\hline Currently married & 17 & 5.7 \\
\hline Divorced/separated & 1 & 0.3 \\
\hline No response & 1 & 0.3 \\
\hline \multicolumn{3}{|c|}{ Religion } \\
\hline Christianity & 292 & 97.3 \\
\hline Islam & 7 & 2.4 \\
\hline Traditional religion & 1 & 0.3 \\
\hline \multicolumn{3}{|c|}{ Ethnicity } \\
\hline Rawat & 206 & 68.9 \\
\hline Uniyal & 35 & 11.7 \\
\hline Hausa & 8 & 2.7 \\
\hline Others & 80 & 16.7 \\
\hline
\end{tabular}


Majority of the respondents have heard about social media ( $\mathrm{n}=299,99.7 \%)$ and majority of the respondents have received information from friends/peers (79\%). The commonest reason for non-use of social media for sexually explicit content was lack of interest (54.3\%).

Table 2: Distribution of the respondents by awareness and social media usage practices

\begin{tabular}{|c|c|c|}
\hline Variables & Frequency $(\mathrm{N}=300)$ & Percentage $(\%)$ \\
\hline \multicolumn{3}{|c|}{ Sources of information on Social media* } \\
\hline Friends/Peers & 237 & 79 \\
\hline School & 155 & 51.7 \\
\hline Television & 121 & 40.3 \\
\hline Siblings & 102 & 34 \\
\hline Radio & 82 & 27.3 \\
\hline Printmedia & 62 & 20.7 \\
\hline Parents & 55 & 18.3 \\
\hline No & 139 & 66.19 \\
\hline \multicolumn{3}{|c|}{ Ever used Social media ( $N=299$ ) } \\
\hline Yes & 286 & 95.7 \\
\hline No & 13 & 4.3 \\
\hline \multicolumn{3}{|c|}{ Reasons for use of social media* $(n=286)$} \\
\hline Access news & 208 & 72.7 \\
\hline Academics & 182 & 63.6 \\
\hline Sex movies and pornography & 173 & 60.5 \\
\hline Access sexual health educational content & 111 & 38.8 \\
\hline Emails & 111 & 38.8 \\
\hline Games & 105 & 36.7 \\
\hline Sports & 31 & 10.8 \\
\hline \multicolumn{3}{|c|}{ Access social media for sexually explicit content } \\
\hline Yes & 173 & 57.6 \\
\hline No (for other reasons) & 113 & 37.7 \\
\hline \multicolumn{3}{|c|}{ Commonest reason for not accessing Social media for Sexually explicit content $(n=113)$} \\
\hline Not interested & 62 & 54.9 \\
\hline It is inappropriate & 25 & 21.8 \\
\hline It is against my faith & 20 & 18 \\
\hline Restrictions on campus & 3 & 2.7 \\
\hline It is addictive & 2 & 1.8 \\
\hline Do not own a smartphone & 1 & 0.8 \\
\hline
\end{tabular}

*Multiple Responses 
Table 3: Distribution of respondents by sexual practices

\begin{tabular}{|c|c|c|}
\hline Sexual practices & Frequency $(\mathrm{N}=153)$ & Percentage (\%) \\
\hline \multicolumn{3}{|c|}{ Ever had sex } \\
\hline Male & 58 & 37.9 \\
\hline Female & 95 & 62.1 \\
\hline \multicolumn{3}{|c|}{ Age at sexual debut, $(n=153)$} \\
\hline$<5$ & 2 & 1.3 \\
\hline $6-10$ & 5 & 3.3 \\
\hline $11-15$ & 27 & 17.6 \\
\hline $16-20$ & 98 & 64.1 \\
\hline $21-25$ & 17 & 11.1 \\
\hline $26-30$ & 4 & 2.6 \\
\hline \multicolumn{3}{|c|}{ Sexually active (had sex in $<3$ months) } \\
\hline Yes & 126 & 82.4 \\
\hline No & 27 & 17.6 \\
\hline \multicolumn{3}{|c|}{ Form of sexual acts respondents practice* } \\
\hline Vaginal/penile & 119 & 77.7 \\
\hline Oral sex & 85 & 55.6 \\
\hline Sexting & 58 & 37.9 \\
\hline Masturbation & 47 & 30.7 \\
\hline Anal sex & 36 & 23.5 \\
\hline \multicolumn{3}{|c|}{ Type of sexual acts respondents practice } \\
\hline Penetrative & 100 & 65.4 \\
\hline Non penetrative & 15 & 9.8 \\
\hline Not specific & 38 & 24.8 \\
\hline \multicolumn{3}{|c|}{ Type of sexual partnerships* } \\
\hline Steady partner (Boy/girlfriend) & 113 & 77.7 \\
\hline Casual contact & 68 & 44.4 \\
\hline Partner met on social media & 60 & $39 / 2$ \\
\hline Commercial sex worker & 32 & 20.9 \\
\hline \multicolumn{3}{|c|}{ Number of sexual partnerships } \\
\hline Single & 97 & 63.4 \\
\hline Multiple & 56 & 36.6 \\
\hline \multicolumn{3}{|c|}{ Ever used condoms } \\
\hline Yes & 124 & 81.1 \\
\hline No & 29 & 18.9 \\
\hline \multicolumn{3}{|c|}{ Frequency of condom use } \\
\hline Consistently & 59 & 47.6 \\
\hline Occasionally & 64 & 51.6 \\
\hline No response & 1 & 0.8 \\
\hline
\end{tabular}

* Multiple Responses 
On analysis, there was no statistically significant $\left(\chi^{2}=0.90329, p=0.301\right) \cdot($ Table-4) association between gender and ever having sex

Table 4 : Association of sexual practices with genders

\begin{tabular}{|c|c|c|c|c|c|}
\hline & & er had se & & Test statistic $(\chi 2)$ & $p$ value \\
\hline Gender & Yes(\%) & No $(\%)$ & Total (\%) & \multirow{4}{*}{0.9032} & \multirow{4}{*}{0.301} \\
\hline Male & $58(19.3)$ & $48(16)$ & $106(35.3)$ & & \\
\hline Female & $95(31.7)$ & $99(33)$ & $194(64.7)$ & & \\
\hline Total & $153(51)$ & 147 (49) & $300(100)$ & & \\
\hline
\end{tabular}

Table 5: Association of sexual practices with social media use for sexually explicit content

\begin{tabular}{|c|c|c|c|c|}
\hline \multirow{2}{*}{$\begin{array}{l}\text { Sexual practices } \\
\qquad(n=153)\end{array}$} & \multicolumn{3}{|c|}{$\begin{array}{l}\text { Accesses Social media for sexually } \\
\text { explicit content }\end{array}$} & \multirow{2}{*}{$\chi 2$ test, $p$ value } \\
\hline & Yes(\%) & No $(\%)$ & Total (\%) & \\
\hline \multicolumn{5}{|c|}{ Ever had sex } \\
\hline Yes & $58(19.3)$ & $90(30)$ & $106(35.3)$ & \multirow{3}{*}{$0.171(0.6795)$} \\
\hline No & $95(31.7)$ & $83(27.7)$ & 194 (64.7) & \\
\hline Total & $153(51)$ & $173(57.7)$ & $300(100)$ & \\
\hline \multicolumn{5}{|c|}{ Sexually active (had sex in $<3$ months) } \\
\hline Yes & $84(54.9)$ & $42(27.5)$ & $126(82.4)$ & \multirow{3}{*}{$15.27\left(0.000^{*}\right)$} \\
\hline No & $7(4.6)$ & $20(13)$ & $27(17.6)$ & \\
\hline Total & $91(59.5)$ & $62(40.5)$ & $153(100)$ & \\
\hline \multicolumn{5}{|c|}{ Type of sexual acts } \\
\hline Penetrative & $68(44.4)$ & $32(21)$ & $100(65.4)$ & \multirow{4}{*}{$8.644\left(0.003^{*}\right)$} \\
\hline Non penetrative & $7(4.6)$ & $8(5.2)$ & $15(9.8)$ & \\
\hline Not specific & $16(10.5)$ & $22(14.3)$ & $38(24.8)$ & \\
\hline Total & $91(59.5)$ & $62(40.5)$ & $153(100)$ & \\
\hline \multicolumn{5}{|c|}{ Number of sexual partners } \\
\hline Single & $73(47.7)$ & $24(15.7)$ & $97(63.4)$ & \multirow{3}{*}{$27.203\left(0.000^{*}\right)$} \\
\hline Multiple & $18(11.8)$ & $3824.8)$ & $56(36.6)$ & \\
\hline Total & $91(59.5)$ & $62(40.5)$ & $153(100)$ & \\
\hline \multicolumn{5}{|c|}{ Use of condoms } \\
\hline Yes & $78(51)$ & $46(30.1)$ & $124(81.1)$ & \multirow{3}{*}{$2.0025(0.157)$} \\
\hline No & $13(8.5)$ & $16(10.4)$ & $29(18.9)$ & \\
\hline Total & $91(59.5)$ & $62(40.5)$ & $153(100)$ & \\
\hline
\end{tabular}

* Statistically significant association $-\mathrm{p}<0.05, \chi 2$ - Chi square test 


\section{Discussion:}

This cross-sectional descriptive study determined the use of social media and its association with sexual practices among undergraduate medical students. In this study, all but one respondent was aware of social media as compared to $100 \%$ awareness in other studies. ${ }^{[22,23]}$ On the source of information about social media, more than seven in every ten of them heard from friends/peers followed by schools. This is in tandem with the findings of other studies. ${ }^{[24,25]}$

From the findings of this study, about $95.3 \%$ of respondents reported ever use of social media and the primary reason was access to news, academics, sex movies and pornography,. This is also in keeping with the findings of other studies. ${ }^{[23,24]}$ This study found that majority of the respondents accessed social media for sexually explicit content. Similar reports have been made elsewhere. ${ }^{[26]}$ The commonest reason for non-use of social media for sexually explicit content was lack of interest which is corroborated by the Media Practice Model, which posits that media use is selective with users focusing on content related to the predominant issues of interest to them. ${ }^{[26]}$

Our study found that the mean age at sexual debut was $17.44 \pm 2.63$ years. This finding relates with the findings of other studies. ${ }^{[27,28]}$ The current study reported that about $42 \%(n=126)$ respondents have engaged in a sexual act in the preceeding three months of the survey. This finding is consistent with the report in another study. ${ }^{[29]}$

It is pertinent to note that though $81.1 \%$ of the respondents who ever had sexual intercourse reported the use of condoms, only less than half of them were consistent. This practice has also been reported by other studies. ${ }^{[29]}$ On the other hand, more than seven in every ten of the respondents who ever had sex reported having steady partnerships. Though there were variations in proportions, this finding agrees with reports elsewhere. ${ }^{[36]}$ About $39.7 \%$ of the respondents who ever had sex, had partners met up on social media, while $20.9 \%$ patronized commercial sex workers, as reported in other studies. ${ }^{[2]}$
In the present study, there was no statistically significant association between ever having sex and gender. However, more female students were found to engage in sexual acts than the males as in other studies. ${ }^{[30]}$

The index study found statistically significant associations between use of social media for sexually explicit content and variables such as being sexually active; type of sexual acts practiced, and number of sexual partners. This finding is consistent with the findings of several studies which showed that use of social media for sexually explicit content had influences on users "sexual practices albeit negatively. ${ }^{[2,5]}$ Implicated in this trend, were factors like the media; especially the social media. Moreover, observationallearning theory suggests that the viewer's characteristics and behavior could be influenced by the character or behavior observed. It thus indicates that exposure to sexual contents on the media could influence reciprocate behavior. ${ }^{[11]}$ Such content is often discussed and exchanged within social networks. ${ }^{[26]}$ Our study found no statistically significant association between use of social media for sexually explicit content and use of condoms. While there is dearth of studies on this subject, similar finding was cited by a group of authors. ${ }^{[31]}$ Further studies are needed in this area.

\section{Conclusion:}

This study examined pattern of social media use among undergraduate students in a private university in Solan, Himachal Pradesh and found high awareness of social media with source of information mostly via friends/ peers. Access to news, academics and viewing sex movies and pornography were the primary reasons for use of social media. Also, accessing sexually explicit content contributes to risky sexual practices. There was no association between ever had sex and gender. There is need for improved multi- sectoral measures (formal comprehensive sex education, peer education programs, school mini-media clubs and targeted behavior change intervention), Media and internet literacy education to control viewing of social media for sexually explicit content, while ensuring that young people's access to sexual health educational content is not compromised.Students who are heavy users, 
should moderate the use of the sites to avoid addiction and create a balance between their offline and online lives while using the sites."This ensures that they assess the quality and source of material that would encourage academic learning and enable them to tackle against the untoward effects of malexposures.

\section{Limitations and strength of the study:} Reporting bias and recall bias could result from this study. These biases however, would have been minimized by the self-administration and anonymity entrenched in data collection, assuring the students that their answers would be strictly confidential and be used for research purposes. First, results are based on self-reported, personal data that could be subject to response bias due to social desirability resulting from participants completing surveys in their school/program environment. This was attenuated by research assistants, not affiliated with the program, administering the surveys. Additionally, the use of personal laptop computers and audio capability increases data dependability. A major strength of this study is in the high response rate (100\%) achieved.

\section{Declaration:}

Funding: Nil

Conflict of Interest: Nil

\section{References:}

1. Johnston L, O'Malley P, Bachman J, Schulenberg J. Monitoring the Future: National Survey Results on Drug Use- Washington, DC National Institute on Drug Abuse (NIDA); 1975. pp. 06-5883.

2. Kaestle CE, Halpern CT, Miller WC, Ford CA. Young age at first sexual intercourse and sexually transmitted infections in adolescents and young adults. Am J Epidemiol. $2005 \mathrm{Apr}$ 15;161(8):774-80. doi: 10.1093/aje/kwi095.

3. Lee J, Hahm HC. Acculturation and sexual risk behaviors among Latina adolescents transitioning to young adulthood. J Youth Adolesc.2010; 39(4):414-27.doi: 10.1007/s10964-009-9495-8.

4. Erikson E. Eight ages of man. Klassiekers van de kinder-en jeugdpsychiatrieII. 1967:258

5. Erikson E. Identity and the life cycle: selected papers. New York: International Universities Press; 1959.

6. Strauch B. The primal teen: What the new discoveries about the teenage brain tell us about our kids. New York, NY: Knopf Doubleday Publishing Group; 2007.
7. Lenhart A. Pew Research Center. 2012. [2017-04-04]. Teens, smart phones \& texting http://www.pewinternet.org/2012/ 03/19/teens-smartphones-texting/webcite.

8. Brown JD, Halpern CT, L'Engle KL. Mass media as a sexual super peer for early maturing girls.JAdolesc Health. 2005 May;36(5) :420-7.doi: 10.1016/j.jadohealth.2004.06.003.

9. Houlihan D, Houlihan M. Adolescents and the social media: the coming storm. J Child Adolesc Behav. 2014;2:e105. doi: 10.4172/jcalb.1000e105.

10. Moreno M. Social networking sites and adolescent health: new opportunities and new challenges. ISJLP. 2011;7:57.

11. Landry M, Vyas A, Turner M, Glick S, Wood S. Evaluation of social media utilization by Latino adolescents: implications for mobile health interventions. JMIR MhealthUhealth.2015 Sep 29;3(3):e89. doi: 10.2196/mhealth.4374. http:/ /mhealth.jmir.org/2015/3/e89/

12. Berry J. Immigration, acculturation, and adaptation. 1997 Jan;46(1):5-34. doi: 10.1111/j.1464-0597.1997.tb01087.x.

13. Livingstone S. Taking risky opportunities in youthful content creation: teenagers' use of social networking sites for intimacy, privacy andself-expression. 2008;10(3):393-411.

14. Moreno MA, Kolb J. Social networking sites and adolescent health. PediatrClin North Am. 2012 Jun;59(3):601-12, vii. doi: 10.1016/j.pcl.2012.03.023.

15. Stockwell MS, Kharbanda EO, Martinez RA, Lara M,VawdreyD,NatarajanK,Rickert VI. Text4Health: impact of text message reminder-recalls for pediatric and adolescent immunizations. Am J Public Health. 2012 Feb; 102(2):e15-21. doi: 10.2105/AJPH.2011.300331.

16. Wong CA, Merchant RM, Moreno MA. Using social media to engage adolescents and young adults with their health. InHealthcare. 2014 Dec 31;2(4):220-4.

17. Borzekowski Dina L G Adolescents' use of the internet: a controversial, coming-of-age resource. Adolesc $\quad M \quad$ e d Clin.2006 Feb;17(1):205-16. d o i : 10.1016/j.admecli.2005.10.006.

18. O'Keeffe GS, Clarke-Pearson K, Council OC. The impact of social media on children, adolescents, and families. Pediatrics. 2011 Apr;127(4):800-4.doi: 10.1542/peds.2011- 0054.

19. Landry M, Gonzales FA, Wood S, Vyas A. New media use and sexual behavior among Latino adolescents. Am J Health Behav. 2013 May;37(3):422-30. doi: 10.5993/AJHB.37.3.15.

20. Frank S. Hyper-texting and hyper-networking examining why too much texting and social networking is associated with teen risk behavior. 141st APHA Annual Meeting and Exposition; November 2-6, 2013; Boston, MA. 2013. Nov 05,

21. Deptula DP, Henry DB, Schoeny ME. How can parents make a difference? longitudinal associations with adolescent sexual behavior. J Fam Psychol. 2010 Dec;24(6):731-9. doi: $10.1037 / \mathrm{a} 0021760$.

22. Di Clemente RJ, Wingood GM, Crosby RA, Sionean C, Cobb BK, Harrington K, Davies SL,HookEW,OhMK. Sexualriskbehaviors associated with having older sex partners:astudy of black adolescent females. Sex Transm Dis. 2002 Jan;29(1):20-4. 
23. Huebner AJ, Howell LW. Examining the relationship between adolescent sexual risk- taking and perceptions of monitoring, communication, and parenting styles. J Adolesc Health. 2003 Aug;33(2):71-8.

24. Killoren SE, Deutsch AR. A longitudinal examination of parenting processes and Latino youth's risky sexual behaviors. J Youth Adolesc. 2014 Dec;43(12):1982-93. doi: 10.1007/s10964-0130053-z.

25. Wight D, Williamson L, Henderson M. Parental influences on young people's sexual behaviour: a longitudinal analysis. J Adolesc. 2006 Aug;29(4):473-94. doi: 10.1016/ j.adolescence.2005.08.007.

26. De Graaf H,VanwesenbeeckI,WoertmanL, MeeusW. Parentingandadolescents"sexual development in western societies. European Psychologist. 2011 Jan;16(1):21-31. doi: 10.1027/1016-9040/a000031.

27. Vyas AN, Landry M, Schnider M, Rojas AM, Wood SF. Public health interventions: reaching Latino adolescents via short message service and social media. J Med Internet Res. 2012 Jul 12;14(4):e99. doi:10.2196/jmir.2178. http://www.jmir.org /2012/4/e99/
28. Gil A, Vega W, Dimas J. Acculturative stress and personal adjustment among Hispanic adolescent boys. J Community Psychol. 1994;22(1):43-54. doi: 10.1002/15206629(199401)22:1<43::AID-JCOP2290220106>3.0.CO;2-T.

29. Kerr M, Beck K, Shattuck TD, Kattar C, Uriburu D. Family involvement, problem and prosocial behavior outcomes of Latino youth. Am J Health Behav. 2003;27Suppl 1:S55-65.

30. Pfeifer J, Masten C, Moore W, Oswald T, Mazziotta J, Iacoboni M, Dapretto M. Entering adolescence: resistance to peer influence, risky behavior, and neural changes in emotion reactivity.Neuron.2011 Mar 10;69(5):1029-36. doi: 10.1016/j.neuron.2011.02.019. https://linkinghub. elsevier.com/retrieve/pii/S0896-6273(11)00117-6.

31. Li X, Feigelman S, Stanton B. Perceived parental monitoring and health risk behaviors among urban low-income AfricanAmerican children and adolescents.J Adolesc Health.2000 